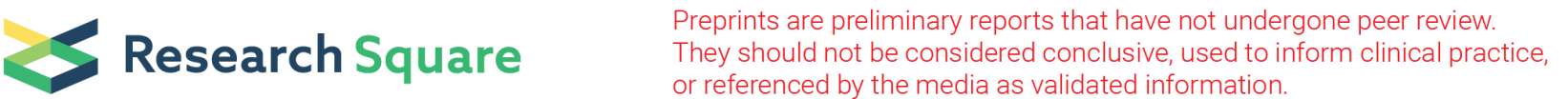 \\ Clinical Characteristics of Mechanically Ventilated Patients Treated in Non-ICU Settings in Japan: A Retrospective Analysis
}

Yoshiaki Iwashita ( $\square$ iwaci1ta@yahoo.co.jp)

Department of Anesthesiology and Critical Care Medicine, Mie University Graduate School of Medicine https://orcid.org/0000-0002-7054-8448

\section{Shinnosuke Morimoto}

Kinan Hospital

\section{Sukenari Koyabu}

Owase General Hospital

\section{Kazuo Maruyama}

Department of Anesthesiology and Critical Care Medicine, Mie University

Hiroshi Imai

Emergency and Critical Care Center, Mie University Hospital

\section{Research}

Keywords: APACHE II, mechanical ventilation, non-ICU, predicted mortality

Posted Date: December 29th, 2020

DOl: https://doi.org/10.21203/rs.3.rs-136891/v1

License: (c) (1) This work is licensed under a Creative Commons Attribution 4.0 International License. Read Full License 


\section{Abstract}

\section{Background:}

The number of patients requiring mechanical ventilation (MV) is increasing worldwide. Patients requiring $\mathrm{MV}$ are commonly managed in an intensive care unit (ICU); however, Japan is unique in that many of these patients are treated in non-ICU settings. The characteristics of these patients, nevertheless, are unknown. We sought to identify disease severity and MV settings of patients in non-ICU settings in Japan.

\section{Methods:}

We retrospectively analyzed the clinical data of Kinan Hospital and Owase General Hospital, where there are no ICUs or ICU physicians. Data for adult patients who required MV for more than $3 \mathrm{~d}$ from January through December 2018 in those hospitals were collected.

\section{Results:}

A total of 171 patients received MV; 29 patients were treated for more than $3 \mathrm{~d}$. Of that subset, the mortality rate was $44.8 \%$ (13 patients). Thirteen patients survived to discharge, and three were transferred to a higher-level facility. The median age of patients treated for more than $3 \mathrm{~d}$ was 80 (72-84) years. The mean Acute Physiologic Assessment and Chronic Health Evaluation II score was $20.9 \pm 8.1$, and predicted mortality was $0.42 \pm 0.25$. Tidal volume per predicted body weight was $8.8 \pm 2.1 \mathrm{~mL} / \mathrm{kg}$; set inspiratory time was $1.6 \pm 0.3 \mathrm{sec}$. Preventable non-ICU death (patients who might have been saved if treated in an ICU setting), was $10.3 \%$.

\section{Conclusions:}

The overall mortality of patients treated with MV in a non-ICU setting in the East Kishu area was not inferior to the mortality if they had been treated in an ICU; however, MV settings should be improved.

\section{Background}

With the rising demand for mechanical ventilation (MV), the number of patients requiring admission to an intensive care unit (ICU) is increasing worldwide (1). Recent and extensive spread of the coronavirus disease 2019 (COVID-19) has further increased the requirement for MV and ICU beds. In many countries, patients treated with MV are managed only in ICUs. However, in some regions or countries, including Japan, some of the patients treated with acute-phase MV are managed in non-ICU settings (2-5). Previously, we showed that $46.4 \%$ of these patients (including those with noninvasive MV) are treated in non-ICU settings in Japan (2). The mortality rate of these patients was higher than in those treated in ICU settings. However, the patients' disease severity and the appropriateness of the ventilator settings were unknown. Therefore, it is not clear that the high mortality of patients treated in non-ICU settings is because the patients were not treated in an ICU or were patients with severe disease who were not 
transferred to a higher-level hospital. We sought to evaluate the detailed data of patients receiving acutephase MV in non-ICU settings. The purpose of this study was to describe the characteristics, including the severity score and ventilator settings, of patients treated with MV in non-ICU settings.

\section{Methods}

We retrospectively analyzed the data of Kinan Hospital and Owase General Hospital, in Mie, Japan. There are no board-certified ICU physicians or board-certified emergency medicine physicians in those hospitals, and there are no ICU nurses in either hospital. The two hospitals are located in the East Kishu area; the ICU facility closest to the hospitals is about a 2-h drive (approximately $150 \mathrm{~km}$ ) by ambulance. The study period was from January through December 2018. The patient flow is shown in Fig. 1. Inclusion criteria in the study were patients requiring MV either through tracheal intubation or tracheostomy treated more than $3 \mathrm{~d}$ in those hospitals and older than 18 years. We only included the patients who had been on MV more than $3 \mathrm{~d}$ because we wanted to exclude patients who were only on short-term MV, such as postoperative MV. Exclusion criteria were terminal cancer, MV after cardiac arrest, and noninvasive ventilation.

We collected the following patient data: age, mortality, arterial pressure, lactate concentration, number of MV days, Acute Physiologic Assessment and Chronic Health Evaluation II (APACHE II) score, outcome (discharge, death or transfe), and MV settings for MV mode, positive end-expiratory pressure (PEEP), fraction of inspired oxygen $\left(\mathrm{FiO}_{2}\right)$, tidal volume, and tidal volume/predicted body weight.

The predicted mortality was calculated using the equation described by Knaus et al. (6).

$\mathrm{R}=\mathrm{e}^{\mathrm{k}} /\left(1+\mathrm{e}^{\mathrm{k}}\right)$

$\mathrm{k}=-3.517+(0.146 \times$ APACHE II score $)$

+0.603 (only if postemergency surgery)

$+($ diagnostic category weight)

This equation is based on the APACHE II score; therefore, this score means the predicted mortality if the patient entered the ICU. We defined "preventable non-ICU death" as patients who died despite having a predicted mortality of less than $50 \%$. This means that the patient might have survived if treated in an ICU setting. This is comparable with preventable trauma death, which is defined as deaths when predicted trauma mortality is less than $50 \%$. Predicted mortality is calculated from the APACHE II score, which is a severity index for patients treated in the ICU. Therefore. a preventable non-ICU death indicates the patients whose chance of survival was more than $50 \%$ if treated in the ICU setting. Continuous variables were expressed as mean \pm SD or median (interquartile range), as appropriate. Continuous variables were compared using the t-test. A $p$-value $<0.05$ was considered significant. Statistical analysis was performed using R statistical software (R Core Team, Vienna, Austria). 


\section{Results}

Data were collected for a total of 171 patients requiring MV in the two hospitals for the 1-year study period. Among them, 93 patients were treated by invasive ventilation, and 29 patients were treated for more than $3 \mathrm{~d}$ with MV. Thirteen patients survived to discharge, 13 patients died, and three patients were transferred to a higher-level facility. The mortality rate was $44.8 \%$ (Fig. 1).

The characteristics of the patients enrolled in the study are shown in Table 1. The median age of the patients was 80 years; the male:female ratio was $21: 8$. The number of cases and deaths are shown in Fig. 2. Mortality in patients grouped by age was $1 / 1(100 \%)$ at $\geq 91$ years, $6 / 12(50 \%)$ at $81-90$ years, $4 / 12(33 \%)$ at $71-80$ years, $2 / 3(66 \%)$ at $61-70$ years, and $0 / 1(0 \%)$ at $<50$ years of age. Th mean arterial pressure was $61 \mathrm{mmHg}$, and lactate level was $31.5 \mathrm{mg} / \mathrm{dL}$. The median duration of MV treatment was 8 (4-19) d, mean APACHE II score was $20.9 \pm 8.1$, and predicated mortality was $0.42 \pm 0.25$. Therefore, the real mortality rate of this patient group was slightly higher than the average predicted mortality. 
Table 1

Patient characteristics

\begin{tabular}{|c|c|}
\hline & $N=29$ \\
\hline Age (years old) & $80(72-84)$ \\
\hline Male (\%) & $21(72.4 \%)$ \\
\hline Systolic Blood Pressure $(\mathrm{mmHg})$ & $90.7 \pm 31.2$ \\
\hline Mean Blood Pressure (mmHg) & $61 \pm 29.3$ \\
\hline Respiratory Rate (/min) & $23 \pm 8.2$ \\
\hline $\mathrm{FiO}_{2}$ & $0.58 \pm 0.24$ \\
\hline $\mathrm{PaO}_{2}(\mathrm{mmHg})$ & $122.7 \pm 71.9$ \\
\hline $\mathrm{PaCO}_{2}(\mathrm{mmHg})$ & $63.1 \pm 54.4$ \\
\hline $\mathrm{pH}$ & $7.32 \pm 0.19$ \\
\hline $\mathrm{Na}(\mathrm{mEq} / \mathrm{L})$ & $135.0 \pm 7.1$ \\
\hline $\mathrm{K}(\mathrm{mEq} / \mathrm{L})$ & $4.2 \pm 0.7$ \\
\hline Crea $(\mathrm{mg} / \mathrm{dL})$ & $1.67 \pm 2.5$ \\
\hline $\mathrm{Ht}(\%)$ & $31.9 \pm 8.4$ \\
\hline WBC $(/ \mu \mathrm{L})$ & $13600 \pm 5400$ \\
\hline Plt $(/ \mu \mathrm{L})$ & $186000 \pm 8700$ \\
\hline Lactate $(\mathrm{mg} / \mathrm{dL})$ & $40.7 \pm 25.1$ \\
\hline MV duration (days) & $8(4-19)$ \\
\hline APACHE II & $20.9 \pm 8.1$ \\
\hline Predicted Mortality & $0.42 \pm 0.25$ \\
\hline
\end{tabular}

A comparison of patients who survived or died is shown in Table 2. The APACHE II score (17.1 vs 24.9, $p$ $<0.01)$ and corresponding predicted mortality rate $(0.32$ vs $0.57, p<0.01)$ were significantly lower in patients who survived. Age (80.2 vs 78.9 years, $p=0.67)$, mean blood pressure ( 60.0 vs $64.5 \mathrm{mmHg}, p=$ 0.65 ), MV duration (10.7 vs $28.0 \mathrm{~d}, p=0.27$ ), and tidal volume/predicted body weight ( $8.39 \mathrm{vs}$ $9.32 \mathrm{~mL} / \mathrm{kg}, p=0.36$ ) were not different between the groups. 
Table 2

Comparison of patients who survived or died

\begin{tabular}{|c|c|c|c|}
\hline & $\begin{array}{l}\text { Survive } \\
\mathrm{N}=13\end{array}$ & $\begin{array}{l}\text { Dead } \\
N=13\end{array}$ & $\mathrm{P}$ value $(95 \% \mathrm{Cl})$ \\
\hline Age & 80.2 & 78.9 & $0.67(-4.6-7.1)$ \\
\hline APACHE II & 17.1 & 24.9 & $<0.01(-12.5-1.47)$ \\
\hline Predicted mortality & 0.32 & 0.57 & $<0.01(-0.39--0.07)$ \\
\hline MV duration (days) & 10.7 & 28.0 & $0.27(-48.9-14.3)$ \\
\hline Mean blood pressure $(\mathrm{mmHg})$ & 60.0 & 64.5 & $0.65(-25.3-16.0)$ \\
\hline $\mathrm{PaO}_{2}(\mathrm{mmHg})$ & 109 & 137 & $0.49(-111-55.5)$ \\
\hline PEEP $\left(\mathrm{cmH}_{2} \mathrm{O}\right)$ & 6.36 & 6.15 & $0.79(-1.43-1.85)$ \\
\hline $\mathrm{FiO}_{2}$ & 0.49 & 0.70 & $0.02(-0.39--0.02)$ \\
\hline TV/PBW & 8.39 & 9.32 & $0.36(-3.02-1.17)$ \\
\hline \multicolumn{4}{|c|}{$\begin{array}{l}\text { APACHE, Acute Physiologic Assessment and Chronic Health Evaluation; } \mathrm{FiO}_{2} \text {, fraction of inspire } \\
\text { oxygen; MV: mechanical ventilation; PBW: predicted body weight; PEEP, positive end-expiratory } \\
\text { pressure; TV: tidal volume. }\end{array}$} \\
\hline
\end{tabular}

To further evaluate the non-inferiority of treating patients with MV in non-ICU settings, we evaluated preventable non-ICU deaths. The number of patients whose predicted mortality rate was $<50 \%$ was $13 / 29$ (44.8\%) patients. Among them, nine patients survived to discharge, one patient was transferred to a higher-level institution, and three patients died. Therefore, the preventable non-ICU deaths were 3/29 (10.3\%) patients.

The MV settings are described in Table 3. The ventilator modes were: assist/control mode $21 \%$, synchronized intermittent mandatory ventilation (SIMV) mode 55\%, spontaneous mode $14 \%$, and data were not recorded in $10 \%$ of patients. The average positive end-expiratory pressure (PEEP) setting was $6.1 \pm 1.7 \mathrm{cmH}_{2} \mathrm{O}$, and inspiratory time setting was $1.6 \pm 0.3 \mathrm{sec}$. Tidal volume per predicted body weight was $8.8 \pm 2.1 \mathrm{~mL} / \mathrm{kg}$. Inspiratory time was not recorded in $21 / 29(72 \%)$, and respiratory rate was not recorded in $9 / 29$ (31\%) patients. 
Table 3

Mechanical ventilator settings

\begin{tabular}{|c|c|}
\hline & $N=29$ \\
\hline Mode of ventilator (n, \%) & $6(21 \%)$ \\
\hline $\mathrm{A} / \mathrm{C}$ & $16(55 \%)$ \\
\hline SIMV & $4(14 \%)$ \\
\hline Spont & $3(10 \%)$ \\
\hline \multicolumn{2}{|l|}{ Data not recorded } \\
\hline $\mathrm{FiO}_{2}$ & $0.58 \pm 0.24$ \\
\hline $\operatorname{PEEP}\left(\mathrm{cmH}_{2} \mathrm{O}\right)$ & $6.1 \pm 1.7$ \\
\hline Inspiratory time (setting) (sec) & $1.6 \pm 0.3$ \\
\hline Peak pressure $\left(\mathrm{cmH}_{2} \mathrm{O}\right)$ & $19 \pm 4.4$ \\
\hline Tidal volume (ml) & $442 \pm 106$ \\
\hline Tidal volume/PBW (ml/kg) & $8.8 \pm 2.1$ \\
\hline
\end{tabular}

\section{Discussion}

We have described the clinical characteristics of patients who were treated with $\mathrm{MV}$ in a non-ICU setting. In the East Kishu area, the number of patients admitted to these two hospitals was 71,000 patients, and the percentage of the people whose age was $>65$ years was $26.6 \%$. In this area, 29 patients were treated with MV at local hospitals that did not have ICU facilities or ICU physicians. The median MV duration was $8 \mathrm{~d}$ (4-19). MV patients-day was 725 in the two hospitals combined. Therefore, patients were treated with MV almost every day in each hospital. This result was comparable with our previous study, in which we completed an attitude survey for physicians in hospitals without ICU facilities, and about $10 \%$ of physicians answered that they treat more than 11 patients with MV in a year (7).

The crude mortality rate was slightly higher than the calculated predicted mortality (44.8\% vs $42.0 \%)$. The calculated predicted mortality rate is the probability of death if the patient were treated in ICU setting. Therefore, the mortality of the patients treated in this area was identical to the mortality of those treated in ICUs. The current mortality data was higher than that of our previous study; in which in-hospital mortality in the non-ICU setting was $41.4 \%$ and $38.3 \%$ in the ICU setting (2); however, that data included patients managed with noninvasive ventilation. Because our current study only included invasiveventilation patients, the mortality should be higher than the previous study. As is expected, the median 
age of the patients was high; however, the ages of the patients were not statistically different between those who survived or died. We have further analyzed the preventable non-ICU deaths, which were defined as the patients who died with a mortality rate $<50 \%$ if treated in an ICU. The rate was $10.3 \%$. There were no similar data with respect to non-ICU deaths; it is difficult to characterize this as high or low.

Comparison with the preventable trauma death data in a city area of Japan, which was 13\% (8), our data do not seem to be too high. Therefore, we can conclude that the patients requiring $M V$ in this area were treated with acceptable mortality in non-ICU settings.

To further describe the appropriateness of the management of patients under MV, the MV settings were analyzed. As a result, the tidal volume per predicted body weight was high, SIMV mode was the most preferred mode of ventilation, and the inspiratory time was set too long. The evidence shows that the tidal volume per body weight should be less than $6 \mathrm{~mL} / \mathrm{kg}$ (9); therefore, the tidal volume should be set lower to prevent ventilator-induced lung injury. However, from the worldwide epidemiological survey on MV setting in the ICU, $34 \%$ of the patients with acute respiratory distress syndrome (ARDS) received more than $8 \mathrm{~mL} / \mathrm{kg}$ of predicted body weight (10). This practice might not be appropriate in the East Kishu area. The SIMV mode was previously the preferred mode, but recent studies revealed that it increased the duration of weaning (11) and may increase patient-ventilator asynchrony $(12,13)$. It is therefore not a preferred mode in ICUs. Surprisingly, respiratory rate was not recorded in 31\% (9/29) of the patients and inspiratory time was not recorded in $72 \%(21 / 29)$ of the patients. Higher inspiratory time also induced patient-ventilator asynchrony and resulted in ventilator-induced lung injury (14). Because patientventilator asynchrony is a relatively new concept, it might be difficult for non-ICU physicians who are not board-certified in critical care to catch up with emerging evidence in the critical care field. These results may indicate that regular updates in standard MV education might improve MV care. With this information in mind, the current results suggest the possibility of managing patients on MV treatment appropriately even in non-ICU settings.

There are two main limitations of this study. First, the study was conducted only in one area of Japan. This result may not represent the nation as a whole. Second, because our main purpose was the description of the characteristics of patients treated with MV treated in non-ICU settings (as well as their MV settings), we have not compared the patients who were transferred or died within $2 \mathrm{~d}$. The initial management may influence the final outcome. Further analysis including many areas of Japan will add to what is known regarding the characteristics of MV management in non-ICU settings.

\section{Conclusions}

The outcomes of patients with MV treated in non-ICU settings in the East Kishu area were not inferior to those of patients treated in ICUs. In addition, the MV settings might not have been based on current evidence. Further analysis, including a wider area may provide more information on patient management using MV in non-ICU settings.

\section{Abbreviations}


APACHE

Acute Physiologic Assessment and Chronic Health Evaluation

ARDS

acute respiratory distress syndrome

\section{Declarations}

\section{Ethics approval and consent to participate}

This study was approved by the Shimane University Institutional Committee (Approval number: 4308, February 12, 2020).

Informed consent of the patients was obtained in an opt-out format.

\section{Consent for publication}

Not applicable.

\section{Availability of data and materials}

The datasets used and/or analyzed during the current study are available from the corresponding author on reasonable request.

\section{Competing interests}

The authors declare that they have no competing interests.

\section{Funding}

None.

\section{Authors' contributions}

YI drafted the manuscript. SM and SK collected and analyzed the data. $\mathrm{HI}$ and KM supervised the manuscript writing. All authors read and approved the final manuscript.

\section{Acknowledgments}

We acknowledge all the members of Kinan Hospital and Owase General Hospital for kindly helping us conduct this study. We also thank Andrea Baird, MD, from Edanz Group (https://en-authorservices.edanz.com/ac), for editing a draft of this manuscript.

\section{References}


1. Carson SS, Cox CE, Holmes GM, Howard A, Carey TS. The changing epidemiology of mechanical ventilation: a population-based study. J Intensive Care Med. 2006;21:173-82.

2. Iwashita Y, Yamashita K, Ikai H, Sanui M, Imai H, Imanaka Y. Epidemiology of mechanically ventilated patients treated in ICU and non-ICU settings in Japan: a retrospective database study. Crit Care. 2018;22:329.

3. Tang WM, Tong CK, Yu WC, Tong KL, Buckley TA. Outcome of adult critically ill patients mechanically ventilated on general medical wards. Hong Kong Med J. 2012;18:284-90.

4. Hersch M, Sonnenblick M, Karlic A, Einav S, Sprung CL, Izbicki G. Mechanical ventilation of patients hospitalized in medical wards vs the intensive care unit - an observational, comparative study. J Crit Care. 2007;22:13-7.

5. Oud L, Garza J. Epidemiology and outcomes of invasive mechanical ventilation without ICU admission in acute care hospitals in Texas: A population-based cohort study. $\mathrm{J}$ Crit Care. 2020;61:107-14.

6. Knaus WA, Draper EA, Wagner DP, Zimmerman JE. APACHE II: a severity of disease classification system. Crit Care Med. 1985;13:818-29.

7. Iwashita Y, Sanui M, Imai H. An attitude survey on doctors treating critically ill patients in hospitals without ICU facilities. J Jpn Assoc Acute Med. 2016;27:175-83.

8. Motomura T, Mashiko K, Matsumoto H, Motomura A, Iwase H, Oda, Shimamura F, Shoko T, Kitamura $\mathrm{N}$, Sakaida K, Fukumoto Y, Kasuyo M, Koyama T, Yokota H. Preventable trauma deaths after traffic accidents in Chiba Prefecture, Japan, 2011: Problems and Solutions. J Nippon Med Sch. 2014;81:320-7.

9. The Acute Respiratory Distress Syndrome Network. Brower RG, Matthay MA, Morris A, Schoenfeld D, Thompson BT, Wheeler A. Ventilation with lower tidal volumes as compared with traditional tidal volumes for acute lung injury and the acute respiratory distress syndrome. $\mathrm{N}$ Engl $\mathrm{J}$ Med. 2000;342:1301-8.

10. Bellani G, Laffey JG, Pham T, Fan E, Brochard L, Esteban A, Gattinoni L, van Haren F, Larsson A, McAuley DF, Ranieri M, Rubenfeld G, Thompson BT, Wrigge H, Slutsky AS, Pesenti A, for the LUNG SAFE Investigators and the ESICM Trials Group. Epidemiology, Patterns of Care, and Mortality for Patients With Acute Respiratory Distress Syndrome in Intensive Care Units in 50 Countries. JAMA. 2016;315:788-800.

11. Esteban A, Frutos F, Tobin MJ, Alía I, Solsona JF, Valverdú I, Fernández R, de la Cal MA, Benito S, Tomás $\mathrm{R}$, et al. A comparison of four methods of weaning patients from mechanical ventilation. Spanish Lung Failure Collaborative Group. N Engl J Med. 1995;332:345-50.

12. Robinson BR, Blakeman TC, Toth P, Hanseman DJ, Mueller E, Branson RD. Patient-ventilator asynchrony in a traumatically injured population. Respir Care. 2013;58:1847-55.

13. Mally PV, Beck J, Sinderby C, Caprio M, Bailey SM. Neural Breathing Pattern and Patient-Ventilator Interaction During Neurally Adjusted Ventilatory Assist and Conventional Ventilation in Newborns. Pediatr Crit Care Med. 2018;19:48-55. 
14. Müller-Redetzky HC, Felten M, Hellwig K, Wienhold S-M, Naujoks J, Opitz B, Kershaw O, Gruber AD, Suttorp N. Witzenrath, M. Increasing the inspiratory time and I:E ratio during mechanical ventilation aggravates ventilator-induced lung injury in mice. Crit Care. 2015;19:23.

\section{Figures}

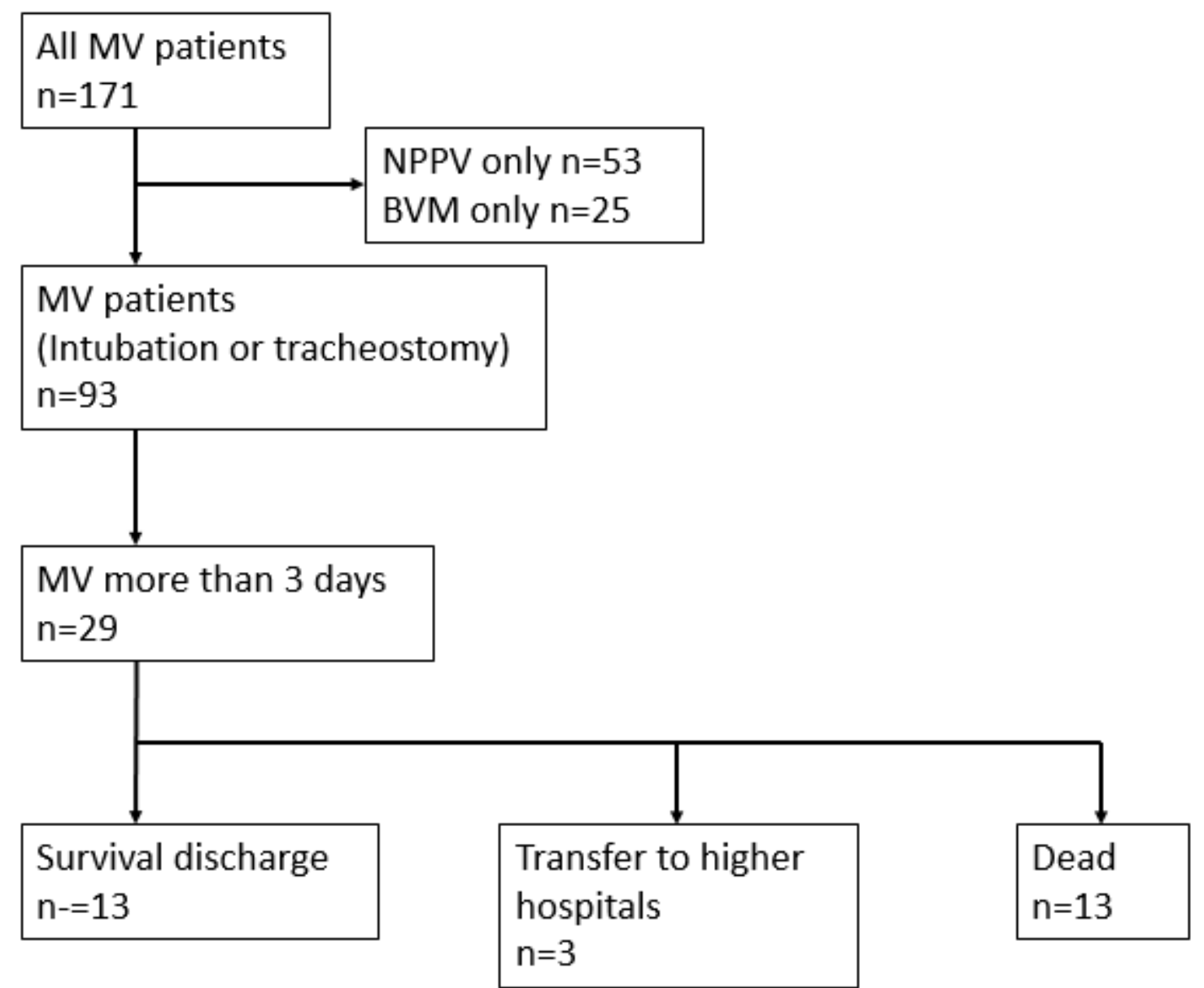

\section{Figure 1}

Patient flow A total of 171 patients received MV in a study period. NPPV or BVM only patients were excluded, and the number of patients received MV more than 3 days within the local facilities were 29. Thirteen survived discharge, 13 has been dead, and 3 transferred to higher hospitals. BVM, bag-valvemask ventilation; MV, mechanical ventilation; NPPV, noninvasive positive-pressure ventilation. 
$\mathrm{N}=29$

Grey bar $=$ all cases

$\mathrm{N}$

Black bar = dead cases, $\mathrm{N}$ (mortality rate (\%))

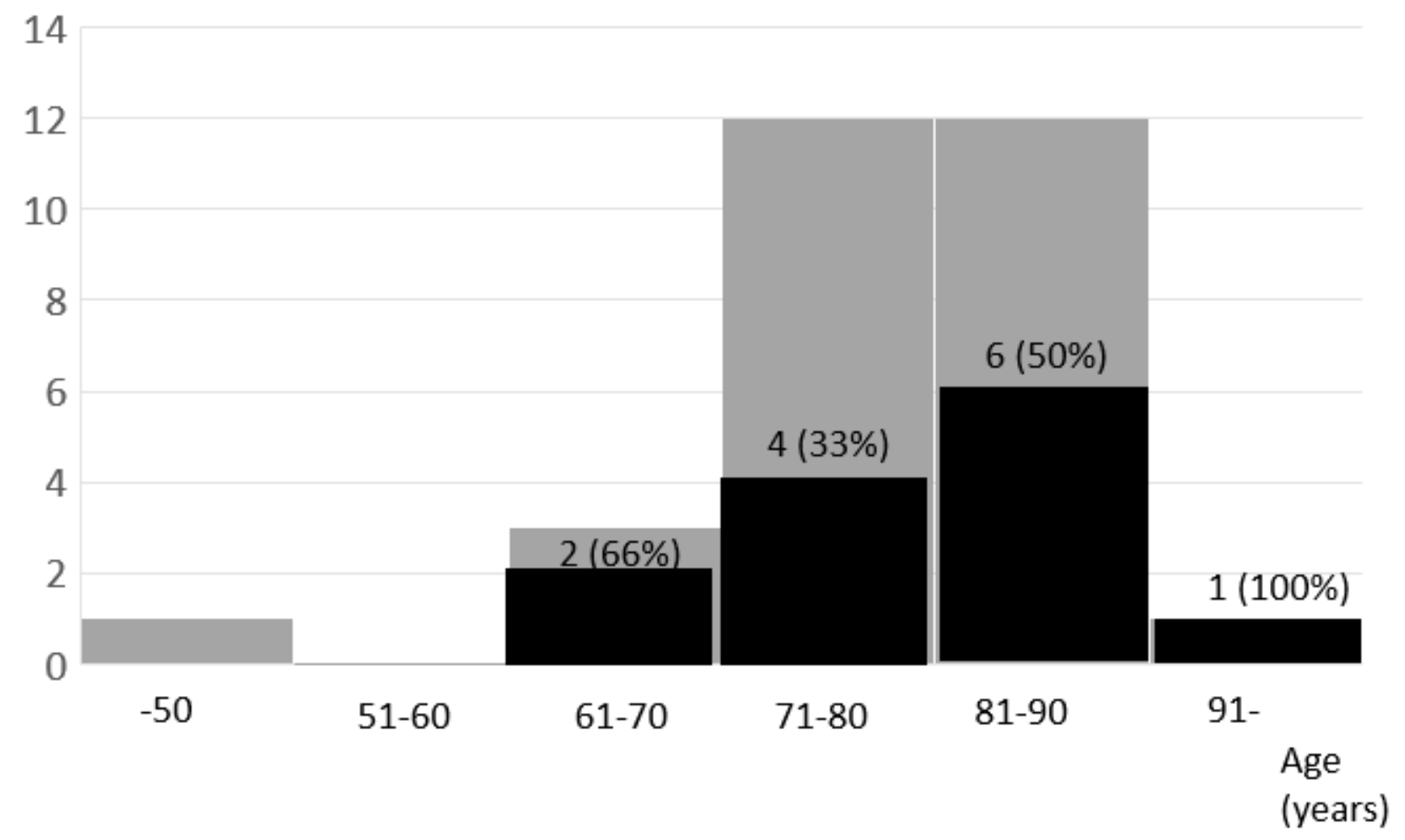

Figure 2

Number of patients and deaths by age This figure shows the number of patients and death by age. Grey bar shows the number of patients, black bar shows the number of dead cases. 